\title{
PENGEMBANGAN KREATIVITAS SUMBERDAYA MANUSIA PELAKU USAHA MIKRO KECIL DAN MENENGAH DINAS KOPERASI UKM TENAGA KERJA DAN TRANSMIGRASI
}

\author{
(Studi Kasus di Kota Yogyakarta)
}

\author{
Sugiyanto ${ }^{1}$, Musoli $^{2}$ \\ ${ }^{1}$ STPMD “APMD” Yogyakarta dan Mahasiswa Program Doktor, Universitas Islam Indonesia \\ probosugiyanto@gmail.com \\ ${ }^{2}$ Mahasiswa Program Magister Manajemen, Universitas Muhammadiyah Yogyakarta \\ musoli27@gmail.com
}

\begin{abstract}
Yogyakarta city which divided into 14 districts and 45 sub-districts has the potential of micro, small and medium business (SMEs) of 22.091 units with various types of products and services. In fact, SMEs are the economic actors of micro, small and medium enterprises that have a large role in addressing unemployment and poverty in the city. Since HR MSMEs are the parts of creative economic actors, it is important that HR of MSMEs to develop their creativity skills. Given the MSMEs actors in Yogyakarta have not maximized in the work, therefore, it needs to maximize their creativity skill.

Through creativity improvement in HR MSMEs, they can maintain and development of new ideas in form of new products, new packaging, new marketing models, and increased partnerships/networks that finally become a powerhouse economy competitive.
\end{abstract}

Keywords : Creativity Development of HR MSMEs

() 2017 JBTI. All rights reserved

Article history : received 01 Ags 2017; revised 03 Ags 2017; accepted 21 Ags 2017

\section{PENDAHULUAN}

Undang-Undang Nomor 20 Tahun 2008 tentang Usaha Mikro, Kecil dan Menengah menunjukan bahwa struktur pelaku ekonomi Indonesia dikelompokan dalam usaha mikro, usaha kecil, usaha menengah dan usaha berskala besar. Usaha Mikro Kecil dan Menengah (UMKM) mampu menyelamatkan perekonomian Indonesia di tengah krisis ekonomi global pada tahun 1998 yang lalu. Dengan demikian UMKM dapat dihandalkan bangsa Indonesia untuk menata ekonomi skala mikro dan menengah kebawah jika UMKM dimanage dengan baik dan mendapat dukungan para pengambil kebijakan sehingga pelaku UMKM memiliki payung hukum dan perlindungan yang kuat untuk menolong dirinya dan membantu mengatasi pengangguran yang berakses pada akar kemiskinan.

Undang-undang nomor 20 tahun 2008 merupakan derifikasi dari pokok pikiran penting Pembukaan UUD 1945 dalam bidang ekonomi antra lain: 1) melindungi ekonomi nasional Indonesia dalam kerangka liberalisasi pasar global., 2). melindungi hak-hak ekonomi warga negara., 3). menjaga kesatuan ekonomi Indonesia dalam kerangka otonomi daerah., 4). mengembangkan suatu system ekonomi yang dapat meletakan peranan negara lebih efektif dalam meningkatkan 
kesejahteraan bagi seluruh bangsa Indonesia secara berkelanjutan., 5). memberikan perlindungan pada kelompok masyarakat atau daerah yang tersisihkan., 6). mengembangkan system keuangan dan fiscal yang efektif guna mendukung pencapaian cita-cita kemerdekaan dengan mekanisme control yang tepat, 7). memiliki format control yang efektif bagi Dewan Perwakilan Rakyat (DPR) terhadap kebijakan ekonomi yang diambil oleh otoritas ekonomi maupun terhadap lembagalembaga yang terkait dengan bidang ekonomi (Adiningsih: 2009).

Ketika UUD 1945 mengalami proses amademen sehingga membuat perubahan yang signifikan antara peranan negara dalam perekonomian dengan mengubah system ekonomi yang dianut oleh Indonesia, dari system ekonomi sosialis (sebelum amandemen) berubah ke system ekonomi pasar sosialis/walfare state (setelah amademen). Ruh dari UUD 1945 yang murni sebelum amandemen dan setelah amademen memiliki semangat yang sama dalam pembangunan perekonomian Indonesia yaitu berupaya mewujudkan masyarakat yang adil dan makmur disusun atas demokrasi ekonomi yang berkeadilan berdasarkan Pancasila dan UUD Negara Republik Indonesia tahun 1945. Para pelaku usaha pada dasarnya telah memiliki jiwa entrepreneurship yang ber-karakter entrepreneur. Renal Khasali (2009:109), Karakter entrepreneur adalah kemampun seseorang didalam mengatasi situasi ekonomi yang sulit dengan mengubah kendala menjadi peluang guna memperoleh keuntungan ekonomi secara progresif berkelanjutan tanpa menimbulkan masalah baru, tabel 1, menunjukan jumlah pelaku usaha mikro, kecil, menengah dan usaha besar di Indonesia tahun 2013.

Tabel 1.

Data UMKM dan Usaha Besar Tahun 2013

\begin{tabular}{|l|l|c|}
\hline \multicolumn{1}{|c|}{ NO } & \multicolumn{1}{|c|}{ JENIS USAHA } & JUMLAH UsahaUnit \\
\hline 1. & Usaha Mikro & 57.895 .721 Unit \\
\hline 2 & Usaha Kecil & 57.189 .393 Unit \\
\hline 3 & Usaha Menengah & 52.106 Unit \\
\hline 4 & Usaha Besar & 5.066 Unit \\
\hline
\end{tabular}

Sumber : Kementrian Koperasi \& UKM Tahun 2013

Undang-Undang Nomor 20 Tahun 2008 bab 1 pasal 1 menjelaskan: Usaha mikro adalah usaha produktif milik orang perorangan dan/atau badan usaha perorangan yang memenuhi kreteria usaha mikro (memiliki kekayan bersih paling banyak Rp 50.000.000; dan memiliki hasil penjualan tahunan paling banyak Rp. 300.000.000; bab IV pasal 6)., Usaha kecil adalah usaha ekonomi produktif yang berdiri sendiri, yang dilakukan oleh orang perorang atau badan usaha yang bukan merupakan anak perusahaan atau bukan bagian baik langsung maupun tidak langsung dari usaha menengah atau usaha besar yang memenuhi kreteria usaha kecil (memiliki kekayaan bersih lebih dari Rp 50.000.000; dan paling banyak Rp 500.000.000; serta memiliki hasil penjualan tahunan lebih dari Rp 300.000.000; serta paling banyak Rp. 2.500.000.000.)., Usaha menengah adalah usaha ekonomi produktif yang berdiri sendiri, yang dilakukan oleh orang perorangan atau badan usaha yang bukan merupakan anak perusahaan atau cabang perusahaan yang dimiliki, dikuasahi, atau menjadi bagian baik langsung maupun tidak langsung dengan usaha kecil atau usaha besar dengan jumlah kekayaan bersih atau hasil penjualan tahunan sebagaimana diatur dalam undang-undang ini (memiliki kekayaan bersih lebih dari Rp 500.000.000; paling banyak Rp 10.000.000.000; memilki hasil penjualan tahunan lebih dari Rp 2.500.000.000; paling banyak Rp 50.000.000.000;) 
Data empirik menyatakan bahwa UMKM memiliki segi positif sebagai kekuatan, yaitu : a). Tahan banting., b). Flexibel., c). Mandiri., d). Efisien (dikerjakan seluruh anggota keluarga. Atau sering disebut usaha rumahan, dan e). Self (or family) financing. Disamping segi positi UMKM juga memiliki segi kelemahan antara lain: a). Usahanya cenderung bersifat informal., b). Skala ekonomi rendah., c). Kecenderungan tidak ada standar operasional prosedur, d). Belum menerapkan prinsip-prinsip manajemen yang baik., dan, e). Tidak disiapkan untuk menjadi besar atau tumbuh.

Walaupun UMKM memiliki kelemahan tetapi UMKM dapat menyerap tenaga kerja sampai 83,9\% dari total penduduk bekerja, paling tinggi pada setiap angkatan kerja pertahun (lihat table 2). Sehingga UMKM sangat berperan terhadap penurunan jumlah pengangguran di Indonesia.

Tabel 2. Perbandingan Jumlah Penduduk Bekerja dan Pengangguran.

Tabel 2.

Data Tenaga Kerja Tahun 2013

\begin{tabular}{|l|l|c|}
\hline NO & \multicolumn{1}{|c|}{ JENIS USAHA } & JUMLAH Tenaga Kerja \\
\hline 1. & Usaha Mikro & 104.624 .466 Orang \\
\hline 2 & Usaha Kecil & 5.570 .231 Orang \\
\hline 3 & Usaha Menengah & 3.943 .365 Orang \\
\hline 4 & Usaha Besar & 3.537 .162 Orang \\
\hline
\end{tabular}

Sumber : Kementrian Koperasi \& UKM Tahun 2013

Mengingat problem yang dihadapi Indonesia dibidang tenaga kerja dan ekonomi saat ini sangat berat sebab fakta yang terjadi: a). Pertumbuhan penduduk setiap tahun meningkat., b). Jumlah angkatan kerja bertambah., c). Perbandingan pekerja dengan pengangguran tidak seimbang., d). Profil sarjana menganggur setiap tahun bertambah., e). Penduduk Indonesia hidup dibawah garis kemiskinan sampai 28,01 Juta orang atau 10,6 persen (BPS 2016). Badan Pusat Statistik pada Agustus 2016 jumlah angkatan kerja Indonesia sebesar 12.544 juta orang, dengan jumlah pengangguran terbuka 7,02 juta orang atau 5,5 persen. Angka pengangguran ini sangat fantastis dan mengejutkan lagi lulusan sarjana yang menganggur sebanyak 695.304 orang dari universitas dan 249.362 orang dari diploma, yang kita sebut sebagai pengangguran terdidik. Problem lain yang signifikan adalah sumberdaya alam Indonesia semakin berkurang, lowongan kerja terbatas, dan angkatan kerja terdidik besar tetapi kebanyakan masih menggantungkan diri pada uluran pekerjaan dari pihak lain sedang manusuia butuh sumber kehidupan yang rutin dan pasti untuk memenuhi kebutuhan primernya.

Sebagai alternatif solusi atas permasalahan bangsa di atas Indonesia harus mampu mencermati karakteristik ekonomi ASEAN sebagai berikut: a). ASEAN sebagai pasar tunggal dan basis produksi., b). ASEAN sebagai kawasan ekonomi dengan daya saing tinggi., c). ASEAN sebagai kawasan dengan pembangunan ekonomi yang merata., d). ASEAN sebagai kawasan yang terintegrasi penuh dengan perekonomian global. Mampukah ASEAN dijadikan media pengetasan permasalahan penduduk dan ekonomi Indonesia melalui UMKM. Mengapa ASEAN menjadi salah satu alternative karena bangsa kita memiliki kekuatan sumberdaya alam sebagai negara agraris dan perairan sebagai penghasil timah nomor satu di dunia, penghasil batubara nomor tiga didunia, Tembaga nomor empat di dunia, Nikel nomor lima didunia, Emas nomor tujuh di dunia dan 
penghasil minyak $80 \%$ di Asia Tenggara serta 35\% Gas Alam Cair di hasilkan di Inonesia. Sangat ironis bahwa penduduk Indonesia hidup di bawah garis kemiskinan sampai 28,01 juta orang.

Mengapa artikel ini dihadirkan dihadapan pembaca berdasarkan emprik penulis selama mengikuti rekam jejak pendamping UMKM di Dinas Koperasi UKM Tenaga Kerja dan Transmigrasi Kota Yogyakarta menunjukan adanya kelemahan para pelaku pada level insaight/pemahaman kreativitas. Atas dasar itu insaight kreativitas perlu mendapat perhatian kusus kepada pihak terkait guna mendrong munculnya ide-ide kreatif dari para pelaku UMKM. Kreativitas dalam kontek ini mendorong keberanian untuk menangkap peluang, inovasi dan menanggung resiko. Berdasarkan evaluasi Dinas Koperasi UKM Tenagakerja dan Transmigrasi telah menyelenggarakan berbagai aktivitas untuk mendorong tumbuh kembangnya isight para pelaku UMKM.

\section{PEMBAHASAN}

Pembangunan adalah proses perubahan yang direncanakan untuk memperbaiki kondisi agar lebih "sejahtera". Perubahan dapat disebut sebagai pembangunan jika perubahan itu memenuhi indikator sebagai berikut: 1). perubahan yang direncanakan, 2). dilakukan perubahan karena kondisinya krisis dan kritis dalam hal sosial, politik ,ekonomi, budaya, teknologi, 3) bertujuan untuk meningkatkan kesejahteraan, 4). subyek dan obyek yang jelas., 5). perubahan yang terjadi berkelanjutan. (Sugiyanto, 2001: 20-23) Sumber yang sama menambahkan walaupun pembangunan itu direncanakan dengan baik tetapi ada kemungkinan terjadi kegagalan pembangunan, penyebab terjadi kegagalan dalam pembangunan antara lain: 1). perencanaan yang tidak tepat atau salah, 2). pelaksanaannya tidak sesuai dengan perencanaan/terjadi penyimpangan, 3). faktor internal seperti sejarah, budaya, dan tidak sesuai dengan kebutuhan, 4). faktor eksternal seperti: dampak kebijakan, globalisasi, krisis, dan bencana.

Permasalahan pembangunan secara umum yang nampak dipermukaan dan segera dicarikan solusi, permasalahan tersebut meliputi: 1). tingginya tingkat pengangguran. 2). rendahnya kualitas ketrampilan dan produktivitas tenaga kerja. 3). masih terbatasnya mutu pelayanan kesehatan masyarakat. 4). banyaknya jumlah penyandang masalah sosial (PMKS). 5). tingginya tingkat kemiskinan. Disisi lain focus pada pengembangan SDM UMKM yang penulis contohkan studi kasus di kota Yogyakarta belum tergarap oleh stakeholders secara maksimal. Sedang stakeholder yang terlibat terhadap keberadaan SDM UMKM di Yogyakarta terdiri dari Pemerintah, BUMNBUMD, Pemilik modal (Perusahaan swasta) dan perguruan tinggi. Hubungan ketiga stakeholder tampak pada gambar 1 di bawah ini.

\section{Gambar 1.}

Hubungan stakeholder SDM UMKM

RELASI TIGA AKTOR

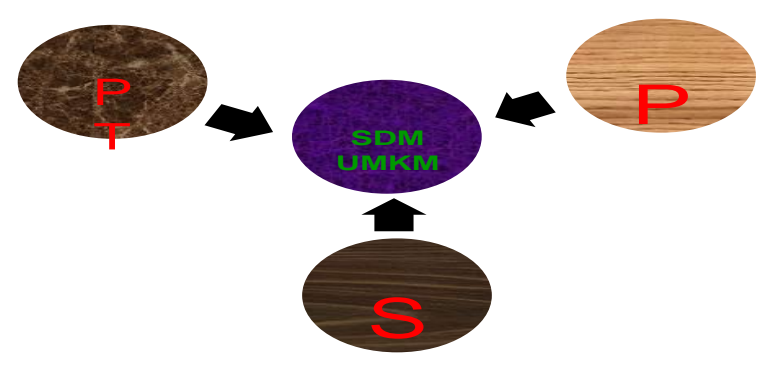


Keterangan gambar:

$\mathrm{P}:$ Pemerintah,

$\mathrm{S}:$ Swasta/pemilik modal dan

PT : Perguruan Tinggi

Jadi warna pelaku UMKM tergantung dari permainan dan kebijakan ke tiga aktor tersebut, Mengadopsi berbagai kebijakan yang telah dilakukan oleh pemerintah propinsi dan pemerintah kota bahwa warna UMKM sangat tergantung dari peran ke tiga aktor tersebut. dan yang menjadi subyek adalah pelaku UMKM. Relasi tiga aktor secara tidak langsung akan menciptakan dinamika manajemen yang sangat bervariatif dan beragam sehingga produk-produk UMKM selalu tampak pengaruh dari yang kuat atas hubungan ketiganya.

Sumber daya manusia (SDM) atau human resources dalam kontek UMKM adalah orang individu atau sekelompok orang atau masyarakat) yang memiliki kinerja, kemampuan, dan potensi yang harus dijaga staminanya karena mereka adalah pelaku usaha dalam sekala mikro, kecil dan menengah mampu berfungsi ganda: Fungsi pertama individu atau masyarakat berperan sebagai obyek pengembangan ekonomi lokal artinya manusia atau masyarakat tersebut menjadi sasaran pengembangan. Fungsi kedua manusia atau masyarakat sebagai subyek pengembangan artinya manusia atau masyarakat tersebut sebagai pelaku dari proses pengembangan UMKM tersebut.

Mengingat pentingnya bahwa SDM UMKM memiliki peran ganda maka manusia perlu dilakukan pengelolaan yang baik. Pengelolaan manusia dalam perkembangan saat ini dinamakan manajemen sumber daya manusia (SDM) Arah pengembangan SDM UMKM fokus pada kemampuan dan potensi SDM yang diharmoniskan dengan sumberdaya non manusia, mengingat semakin majunya teknologi, perkembangan informasi, tersedianya SDA, modal dan fasilitas jika tanpa SDM maka tujuan pengembangan mustahil tercapai.

Manajemen Sumber Daya Manusia semakin berperan strategis dalam organisasi karena mempunyai dampak yang berkelanjutan bagi organisasi (Tjahjono, 2015). Kenooy (1990), mengemukakan bahwa pengembangan SDM adalah suatu metode memaksimumkan hasil dari sumber daya tenaga kerja dengan mengintegrasikan MSDM ke dalam strategi pengembangan. Mengingat pentingnya SDM dalam pengembangan maka perlu adanya upaya pemelihara SDM, sebab SDM merupakan asset perusahaan/usaha sehingga tidak saja dikembangkan tetapi juga perlu dipelihara, baik secara fisik, mental dan spiritual. Pemeliharaan SDM dimaksudkan sebagai suatu kegiatan manajemen untuk mempertahankan stamina SDM didalam melakukan peran dalam proses penguatan UMKM.

Faktor-faktor pendorong adanya pemeliharaan SDM antara lain: 1). SDM merupakan modal utama bagi UMKM jika tidak dipelihara akan menimbulkan kerugian bagi UMKM itusendiri, 2). SDM UMKM adalah manusia yang mempunyai kelebihan, kekurangan, emosi dan perasaan yang mudah berubah akibat perubahan lingkungan sekitar di mana UMKM tersebut tumbuh kembang. Sedang tujuan dari pemeliharaan SDM UMKM antara lain: 1). Menciptakan suasana hubungan antar manusia dalam system kerjasama yang harmonis dan kebersamaan baik dalam satu UMKM maupun dalam organisasi UMKM, 2). Meningkatkan loyalitas SDM terhadap proses perjalanan UMKM, 3). Memberikan perlindungan rasa aman, rasa bangga sehingga timbul perasaan semakin mencintai usahanya., 4). Meningkatkan rasa persatuan dan kesatuan yang saling hormat menghormati dan bersedia menghargai atas kelebihan dan keterbatasan masing-masing individu baik dalam satu UMKM maupun dalam organisasi UMKM. 


\section{A. Faktor-Faktor Penyebab Pertumbuhan UMKM Di Yogyakarta}

Menurut Evertt S. Lee (1970) faktor yang mempengaruhi seseoang mengambil keputusan untuk melakukan mobilitas ada empat yaitu: 1). Faktor yang terdapat didaerah asal, 2). Faktor yang berada di daerah tujuan, 3). Faktor rintangan antar dan 4). Faktor individu. Keempat faaktor tersebut memiliki andil besar terhadap tumbuh kembangnya UMKM di Yogyakarta. Secara rinci faktor tersebut dapat diringkas menjadi dua faktor yaitu primer dan sekender.

Faktor penarik utama/primer yang mendorong tumbuh kembangnya UMKM di Yogyakarta adalah Predikat kota Yogyakarta sebagai kota pendidikan, kota budaya, kota pariwisata, kota batik dunia serta predikat Yogyakarta sebagai kota Perjuangan dan Keistimewaan termasuk didalamnya sebagai sebutan "Indonesia mini" Dari berbagai predikat tersebutlah banyak publik menaruh perhatian terhadap Yogyakarta. Bentuk perhatian publik ditandai dengan peminat anak bangsa dari berbagai daerah dan negara lain belajar/studi di Yogyakarta, masyarakat luas melakukan aktivitas wisata ke Yogyakarta, serta banyaknya berbagai instansi menyelenggarakan berbagai aktivitas bisnis dan aktivitas lainya di kota Yogyakarta.

Faktor Pendorong sekunder, foktor ini ditunjukan dengan adanya sesuatu yang menarik dari pihak luar dan fasilitas yang tersedia di Yogyakarta serta aksesibilitas menuju ke Yogyakarta yang sangat mudah terjangkau dan dalam situasi yang aman serta nyaman. Faktor primer ada dukungan dari kepercayaan pendatang terhadap power kota Yogyakarta yang istimewa dan penduduk yang terkenal dengan ramah, sopan dan berbudaya tinggi.

Semua aktivitas pendidikan, pariwisata, bisnis dan lainnya inilah yang menjadi pasar para pelaku UMKM dan sekaligus menjadi media promosi serta ada hubungan simbiosis mutualisme, artinya bahwa sebagian pendatang/pengunjung ke Yogyakarta sebagian membawa bahan baku yang dipergunakan produksi para pelaku UMKM dan mereka pergi meninggalkan Yogyakarta membawa produk hasil UMKM. Diantara sekian banyak variabel dari dinamika manusia yang paling tinggi kontribusinya terhadap produk UMKM adalah dunia pendidikan (mahasiswa dan pelajar) dan pariwisata.

\section{B. Bentuk-Bentuk Penguatan SDM UMKM}

Potensi UMKM di Kota Yogayakarta berjumlah 22.091 unit usaha terbagi dalam empat jenis usaha yaitu: 1). industri 4545 unit, 2). jasa perdagangan 16853 unit, 3). produksi 546 unit, dan 4). pertanian 147 Unit (sumber: data primer Disperindagkoptan 2010). Berdasarkan data di atas pemerintah kota Yogyakarta telah melakukan berbagai aktivitas untuk kepentingan perlindungan, pengembangan dan penguatan UMKM agar keberadaan UMKM di Yogyakarta mampu bertahan, berkembang dan berkualitas, sehingga produk-produk UMKM berani bersaing di kalangan usaha mikro kecil dan menengah baik di pasaran lokal, nasional dan pasar global.

Pelaku UMKM memiliki kekuasaan, kekuasaan merupakan kemampuan latten untuk mempengaruhi tindakan orang lain pemikiran dan emosi (RGH Siu, 1979,p.31). merupakan energy social untuk ditransformasikan menjadi kekuatan kinestetic. Jeffrey Pfeffer (1981) kekuasaan berefek pada tanggungjawab pada penampilan tugas agar lebih kritis pada organisasi hal ini berdampak yang luar biasa. Artinya pelaku UMKM menjadi memiliki power/kekuasaan, status. Secara empiris pelaku UMKM adalah manusia, ada yang bersifat individu maupun kelompok, kelompok individu sebagai SDM UMKM memiliki lima kekuasaan sosial, French dan Raven 1959, mengidentifikasi lima kekuasaan sosial yaitu kekuasaan reward, persepsi dari kekuasaan, paksaan kekuasaan ligitimasi (otoritas organisasi/pemilik usaha), kekuasaan referensi (melalui asosiasi/jaringan) dan kekuasaan ahli (kekuasaan keahlian/pengetahuan) Wujud pengembangan kreativitas Kota Yogyakarta dalam mengembangan SDM UMKM antara lain: 


\section{Pengembangan kreativitas.}

Kreativitas Sugiyanto (2009) adalah orang atau individu atau kelopok boleh melakukan apa saja, kapan saja, dimana saja, dengan siapa saja, tetapi selama beraktivitas individu dan atau kelompok tidak boleh melanggar norma. Baik norma agama, norma pergaulan, sopan santun dan adat istiadat. Atas itu kreativitas tidak dibatasi oleh waktu, ruang dan jaringan. Pengembangan kreativitas di Yogyakarta dimotori oleh Dinas Perdangan Perindustri Koperasi dan Pertanian bekerjasama dengan Perguruan Tinggi dan pemilik modal atau pengusaha besar, yang dilaksanakan secara kontinyu. Arah pengembangan kreativitas untuk meningkatkan insight/pemahaman SDM UMKM tidak saja dari unsur kecerdasan intelektual (IQ), tetapi lebih ningkatkan memberikan rangsangan pada kecerdasan sosial, kecerdasan emosional, kecerdasan speritual dan kecerdasan kinestetik. Malcocolm Gladwell (2008) yang telah meneliti kesuksesan manusia menemukan karya-karya besar ternyata tidak ditentukan tingginya scor IQ. John C. Maxwell dalam buku Talent is Never Enough (2007), Maxwell mengatakan bakat itu hanyalah sebuah kesempatan namun untuk menjadi sesuatu bakat itu harus diasah agar ia mengeluarkan aura cahayanya dan menemukan pintunya. Namun lebih dari itu kesempatan atau sebuah potensi harus bergerak menemui pintunya. Jadi pengembangan kreativitas SDM UMKM berkecenderungan sebagai rangsangan agar bakat yang dimiliki oleh SDM UMKM dapat bergerak menuju pintu sukses dengan ditandai akan berubah cara berfikir dengan pelaku yang diarahkan pada konsep kreative. Konsep kreative merupakan proses mencari nilai tambah dengan berfikir kreativ melalui empat model (dari atas ke bawah, dari bawah ke atas, dari belakang ke depan, dari depan kebelakang, diagonal, dll). Kreativ merupakan proses berfikir merangsang untuk menyelesaian masalah/tantangan dan pada akhirnya melahirkan berbagai ketrampilan kreatif. SDM UMKM berani menambah, mengurangi, memperbesar dan memperkecil produk. Kreativitas SDM UMKM muncul karena mereka menemukan data/ fakta, menemukan masalah dari data tersebut, lalu berani menciptakan ide sebagai solusi dan mensoalisasikan kepada publik.

2. Menyediakan wadah atau tempat. "Wadah yang telah disediakan oleh pemerintah Kota Yogyakarta adalah "Griya UMKM" sebuah banguan/gedung yang presentatif untuk pertemuan para UMKM, pertemuan UKM dengan pemerintah dan birokrat, pertemuan UMKM dengan bayer, serta berfungsi sebagai etalase produk-produk UMKM, Lokasi Griya UMKM berada di jalan Tamasiswa Yogyakarta yang setiap hari buka dari pukul 08.00-21.00. Bangunan ini terdiri dari ruang metting, ruang pameran, office, gudang dan ruang latihan serta ruang informasi. SDM dan biaya operasional Griya UMKM dibebankan pada APBD pemerintah kota Yogyakarta.

3. Pembinaan manajemen, pembinaan manajemen pada prinsipnya bagian lanjutan dari pengembangan kreativitas. Pembinaan manajemen, yang terdiri dari manajemen admistrasi (pembukuan sederhana), manajemen pemasaran, manajemen produksi, majamen pengemasan, dan manajemen pengembanagn jaringan serta pengembangan SDM yang fokus pada pengembangan kreativitas. Pengembangan kreativitas dimotori oleh Dinas Perindustrian Perdagangan Koperasi dan Pertanian bekerjasama dengan Perguruan Tinggi dan pemilik modal atau pengusaha besar, yang dilaksnakan secara kontinu guna mendorong lahirnya ide-ide baru SDM UKM yang tertib administrasi dan berkelanjutan.

4. Memfasilitasi Ekspo UMKM baik didalam kota ataupun keluar kota, salah satu contoh expo yang dilakukan tahun 2011 adalah mengikuti program pameran Batik Nusantara di City Tamrin Jakarta selama tiga bulan dengan dana APBD.

5. Konsultasi online dan kinik bisnis, aktivitas ini Dinas Perindustria Perdangan koperasi dan Pertanian berfungsi sebagai fasilitator dan mediator sedang para tenaga ahli diambilkan dari berbgai perguruan tinggi serta dinas terkait.

6. Payung hukum Peraturan Daerah Kota Yogyakarta nomor 4 Tahun 2011 Tentang Usaha Mikro Kecil dan Menengah (UMKM) sebagai bukti keseriusan pemerintah kota Yogyakarta dalam 
praktek pemberdayaan masyarakat bagi kelompok marginal agar bermartabat dan eksis berbasis potensi local.

7. Yogyakarat sebagai kota toleransi

Strategi yang ditempuh Pemerintah Kota Yogyakarta dalam mengembangkan Kreativitas SDM UMKM antara lain: 1). UMUKM bukan dibesarkan tetapi disehatkan membuat dan menetapkan Karakter, 2). .Strategi mencari patner, 3). Kelahiran UMKM-UMKM baru baik karena situasi (kepepet, disiapkan oleh keluarga/kelompok serta yang lahir secara kebetulan dan hoby. Strategi pemasaran. Untuk mendukung program ini Dinas Perdagangan Perindustrian Koperasi dan Pertanian bekerjasama dengan pihak perguruan tinggi, perbankan, perusahaan berskala besar dan lembaga-lembaga lain yang terkait.

Atas itu pengembanga UMKM diupayakan berkelanjutan dan mengacu pada kondisi iklim usaha global dan pemanfaatannya potensi lokal yang berwawasan lingkungan, diantaranya: 1). menjaga kelangsungan hidup UMKM dengan cara melestarikan fungsi dan kemampuan ekosistem bisnis yang mendukungnya, baik secara langsung maupun tidak langsung. 2). memanfaatkan sumberdaya lokal berbasis teknologi agar teknologi pengelolaan mampu menghasilkan produk secara kontiyu. 3). memberi kesempatan dan ruang kepada UMKM agar mampu berkembang bersama-sama baik dalam kurun waktu yang sama maupun kurun waktu yang berbeda secara berkelanjutan. 4). meningkatkan dan melestarikan kemampuan SDM UMKM untuk menjadi pemasok usaha berskala di atasnya yang berdaya saing tinggi. Dengan memperhatikan core problem di atas maka pengembangan SDM UMKM dapat mempertahankan hidup di dalam iklim usaha karena adanya pertumbuhan UMKM dan usaha lain yang skalanya lebih besar maupun selevel dengan UMKM.

\section{KESIMPULAN}

Agar UMKM tetap eksis dan berkembang seiring cepatnya pertumbuhan pasar bebas pemerintah beserta jaringan mitra segera mengambil sikap untuk menguatkan UMKM, dengan langkah-langkah sebagai berikut:

A. Dengan lahirnya UU No. 20 Tahun 2008 mendorong masing-masing Provinsi, Kabupaten dan Kota memebuat regulasi tentang Peraturan Daerah UMKM, dan Perda tersebut benar-benar mampu menjadi payung UMKM serta mendorong terbentuknya asosiasi UMKM sejenis guna melawan penindas dengan modal besar, Regulasi Pemerintah Kota Yogyakarta dikeluarkannya Perda No 4 Tahun 2011 tentang UMKM.

B. Pemerintah harus memfasilitasi pengembangan UMKM melalui jaringan pemilik modal, perguruan tinggi, pelaku usaha besar, BUMN, BUMD dan lainya dioptimalkan agar dapat bergandengan dengan UMKM.

C. Pengetaskan kemiskinan melalui UMKM akan menumbuhkan rasa bangga masyarakat bawah UMKM mampu bangkit atas kesadaran diri dan menolong orang lain sebagai tenaga kerja dilingkungannya.

D. Pelaku UMKM ini dijadikan gerakan kreativitas yang merata sebab SDA Indonesia berlimpah di pelosok tanah air, sedang yang mengembangkan dan memanfaatkan masih tersentral pada daerah tertentu.

E. Paran mitra diatas dapat memfasilitasi dalam bentuk pengembangan modal lunak, pemasaran, menyelenggaran pelatihan penguatan kapasitas SDM. 
F. Memfasilitasi pembentukan asosiasi usaha mikro sejenis, seperti asosiasi penjual bakso, asosiasi produksi tas dengan bahan baku sampah, asosiasi tukang sol sepatu, dll.

Upaya-upaya di atas merupakan proses untuk mewujudkan prediksi organisasi kerjasama ekonomi dan pembangunan Organization for Economic Co-Operation Development (OECD) dalam memprediksi pertumbuhan ekonomi Indonesia 2012-2016 yang diperkirakan mencapai 6,6\% tertinggi dibanding Negara ASEAN lainnya, jika prediksi tersebut dapat terwujud maka kita yakini bahwa situasi kesejahteraan rakyat Indonesia kususnya pelaku UMKM akan mengalami perubahan pada ranah peningkatan kesejahteraan.

\section{DAFTAR PUSTAKA}

Adiningsih, 2009, Ekonomi untuk Rakyat : Antara Kebijakan Pro Poor Versus Neoliberal, PP Muhammadiyah, Yogyakarta.

Ciputra, 2009, Ciputra Quantum Leap “Entrepreneurship Mengubah Masa Depan Bangsa dan Masa Depan Anda" Universitas Ciputra.

French, J.R.P, \& Raven, B., 1959, Basis Dari Kekuasaan Sosial. D Cartwright \& A. Zander (Eds), Studi pada Kekuasaan Sosial (pp.150-167). Ann Arbor, MI: Universitas Michigan, Institute Penelitian Sosial.

Gregory, M., 2004, Principles of Economics : Pengantar Ekonomi Makro, Edisi ke 3.

Mulyani, 2011, Perdagangan Bebas via www.geogle.co.id, 15 Januari 2010.

Fikri, J.A., 1999, Resources Management, AIMI, Indonesia.

Gunarwan, S., 2002, Analisis Mengenai Dampak Lingkungan, Gajah Mada University Press.

Peraturan Kota Yogyakarta Nomor 4 Tahun 2011, Tentang Usaha Mikro, Kecil dan Menengah, Dinas Perindustrian Perdagangan Koperasi dan Pertanian Kota Yogyakarta.

Rhenald, K., 2010, Wirausaha Muda Mandiri, PT. Gramedia Pustaka Utama, Jakarta.

Sugiyanto, 2001, Lembaga Sosial, Globalindo, Yogyakarta.

Sugiyanto, 2009, Sisi Lain Soft Skill's Studi Entertainment, ”APMD Press" Yogyakarta.

Sugiyanto, 2004, Yogyakarta Kota Pendidikan dan Ekonomi Alternatif, Jurnal "Cakrawala pendidikan edisi XXII. No.3, Lembaga Pengabdian Kepada Masyarakat UNY Yogyakarta.

Siu, R.G.H., 1979 Seni Kekuasaan. New York : John Wiley \& Sons.

Tjahjono, H.K. 2015. Manajemen Sumberdaya Manusia. VSM MM UMY

Zulkarnain, 2003, Membangun Ekonomi Rakyat, Adicita Karya Nusa, Yogyakarta. 